\title{
Research and Practice of Teaching Reform of Electronic Information Specialty
}

\author{
SHUANG-DE ZHANG, LONG ZHOU \\ Wuhan Polytechnic University, Wuhan 430023, P. R. China \\ 2356755232@qq.com
}

Keywords: electrical information engineering; The teaching reform; Cultivation of talents

\begin{abstract}
In this paper, combined with the characteristics of the development of electric information specialty update fast, strong applicability, the reform of the curriculum system, strengthening the training of practical teaching and students' ability of innovation of science and technology, improve the comprehensive quality of electrical and Information Engineering students.

School of Electrical and Electronic Engineering offers the following undergraduates specialties: automation, electrical engineering and automation, electronic information engineering, communication engineering, and telecommunication science. These specialties have the following two characteristics: firstly, these specialties all belong to electrical information engineering, and electronic information discipline is one of the fastest growing disciplines in recent decades. Our teaching contents and curriculum system must keep up with the development of updating science and technology to cultivate talented person suitable for talent market; secondly, The electronic information engineering is a highly practical professional, which requires the students have a strong practical ability to be qualified for the need of talent market [1-6]. In recent years, we have carried out a series of teaching reforms taking these characteristics into consideration, together with the overall objectives of higher education. Our reforms focus on course system, teaching contents and teaching methods to strengthen the practical ability and theoretical knowledge of the students. We propose a new teaching model, i.e. "Two platforms (platform for general education, platform for innovative education), three levels(basic level, intermediate level, and innovative level), three modules(core course module, training module, and innovative module )" teaching mode to cultivate the students' ability.
\end{abstract}

\section{Reform the Curriculum System, Cultivate Students' Practical Ability}

The traditional mode of engineering education emphasizes the students' mastery of professional knowledge, while the cultivation of student's engineering practice ability and innovation ability is not enough. The students of this kind of education can not meet the requirements of the society in the new century. In order to cultivate qualified undergraduates, as a regular institutions of higher learning, we must actively explore new teaching method to develop students' engineering practice ability and creative ability for further research and practice conforming to national conditions and school situation. To formulate talent training plan to satisfy the needs of the current social development and economic construction, to build scientific and reasonable curriculum system are the goal we have been working hard over the years. In this respect, we mainly do the following:

Firstly, we implement the generalist education to strengthen the cultivation of students' basic knowledge, i.e. we have the general education for the first two years after students' recruitment before they move on to the final two-year professional study, which lay a good foundation for a liberal education. We have revised the talent training plan. The revised talents training plan adopts platform module structure of teaching, including general education platform, the discipline foundation platform, professional foundation platform, professional direction module and optional courses. Of which, general education platform ensures that students have a solid natural science, and social science foundation, have a good accomplishment in humanities and arts, and develop good language proficiency both in English and Chinese. In addition, we set some courses such as some interdisciplinary subjects to meet the needs of students' interests and employment orientation.

Secondly, we have to cultivate students' professional technology and skills by constantly updating a the teaching content, introducing the latest knowledge and technology to students and making them adaptable to the development of electronic information technology so as to meet the 
needs of talent market. The development of electronic information technology is rapid with each passing day. Only by keeping in time can we not fall behind the time. What's more, interdisciplinary foundation courses in electrical information categories ensure students to have a wide and solid theoretical knowledge and acquire skills of electronic technology, computer technology, network and communication, and software design and etc.

Thirdly, professional orientation module ensure that students have the professional theoretical knowledge and practice ability. We set up professional orientation module design, emphasizing the connection and course fusion between the professional orientation module and the other related modules. With the development of science and technology, electronic information engineering, communication engineering, automation, electronic science and technology, electrical engineering and automation professional increasingly penetrate each other, which demands a growing convergence of discipline foundation. With fast updating professional knowledge, solid discipline foundation is more important for the development of the graduates in the future. The gravity of undergraduate education moves down to the first two-year generalist education, namely, the professional characteristics of a certain specialty gradually fade, subject characteristic gradually increases. In the optional courses of professional direction, we set interdisciplinary selective courses, to ensure that the students according to their needs and interests in electric information platform to master more extensive professional knowledge, so as to meet the needs of student's personal development.

Fourthly, we have done in several ways to strengthen the construction of experimental courses, increase the comprehensive and design experiments, cultivate students' innovative practice ability, with particular emphasis on the ability of knowledge discovery. We have set up comprehensive and design experiments in experiment teaching since 2003 to develop students' creative spirit and ability of application, and train composite high-level engineering and technical personnel. The experiment teaching is based on electrical and electronic experimental teaching demonstration center of Hubei province and school-financed comprehensive industrial automation PLC laboratory in 2004. These experiment equipment adopts modular design, can complete a variety of division of experiments of software and hardware to meet the requirements of each course. Most of experiment contents contain the basic requirements and advanced requirements to meet the needs of comprehensive and design experiments teaching, which can effectively train and improve students' design debugging ability in application system, help students to combine the contents of the courses, to digest what they have learn, and to have a clear idea of a systematic concepts of their professional study.

\section{Establish "Three levels and Three modules" New Experiment Teaching System of Electrical Information}

The construction of experiment practice teaching system is in relation to the quality of personnel training. What the experiment teaching focus on is students' ability, their personality, and the basic principle of cultivating their creative consciousness. we highlight multi-layered, personality-oriented, inside and outside classroom combined experiment practice teaching system and training mode. The experiments are divided into three different levels, corresponding to basic experiment (general education), design and integrated experiment and innovative experiment (innovation education). Thus we have formed a pyramid of experiment teaching which helps students transform their theoretical knowledge to practical ability, so that the students can master the basic experimental operation method and then develop their scientific thinking ability and the innovation design ability. By so dong, on one hand, our experiment teaching can meet the needs of students in different levels; on the other hand, top students can fully develop their potentials according to their aptitude.

Experiment practice teaching are carried out respectively through two experimental platform (platform for general education, innovation education platform), and three levels (basic level, intermediate level, and innovative level), three modules(core course module, training module, and innovative module) .

\section{To Establish Science andTechnology Innovation Base to Cultivate Creative Talents}

In order to help the students to participate in scientific and technological innovation activities, we set up a school level undergraduate science and technology innovation base, equipped with specialized simulators, MCU, DSP embedded system, digital oscilloscope, etc, to encourage 
students to take part in science and technology innovation activities. Besides, teachers with more teaching experience and excellent teaching and practice ability are carefully chosen to be their tutors. There are 10 teachers of several major research background selected to provide guidance for undergraduates for their innovation activities of science and technology. Students' scientific and technological innovation activities are in the form of modes as follows:

(1) The mode of extracurricular science and technology association. We have multi-level electronic science and technology activities to provide professional training opportunity for students of different grades. Those activities vary from freshman to senior students. Students' association of science and technology activity bases is equipped with small electronic products installation and debugging equipment, which is used as the student's extracurricular activity base; Activities base is open to students, students can come to the base to have science and technology activities at any time. Association actively organizes all kinds of electronic science and technology activities to develop students practical ability, such as electronic exhibition, model competition, free repair household appliances for residents in the neighborhood on weekend and so on. Tests show that students who have participated in the base of extracurricular activities of science and technology outdo the students who have not participated in scientific and technological activities in innovation consciousness and practice ability.

(2) The electronic design contest mode. Taking the national electronic design contest as an opportunity, the innovation experimental base is established to cultivate students' innovation ability, cooperation spirit and learning style of combination of theory with practice and improve students' electronic design ability, which creates the conditions for students to stand out. During the process of competition training, we have explored a set of effective management mode and set up the competition mechanism to ensure the top students' selection and training.

(3) The research mode. We encourage teachers to absorb some of the students to take part in their research project, and provide them with the necessary laboratory equipment. There are many students to participate in teacher's scientific research project in recent years. It is of great benefit to those students who take part in their tutor's research project. After working with their tutor for some time, both their theoretical knowledge and practical ability are greatly developed. Those students took part in the national and provincial contest and won a lot of awards

\section{Conclusion:}

Through years of exploration and practice, we have obtained the great achievement in talent cultivation which can be illustrated in three aspects: (1) good results from all kinds of college students competition. In recent years, we have won one second prize of national undergraduate electronic design contest, and three first prize 7 second prize, more than a dozen successful participative prize in hubei division. (2) the high employment rate and employment quality. The students with high comprehensive quality are hardworking and willing to delve into the work. They soon win their employer's affirmation. Employment rate in recent years has stayed above 90\%. A number of students each year to the Huawei company, Shanghai Bell company, Wuhan Iron and Steel company, Wuhan Tobacco Group and other famous enterprises. (3) High graduate entrance rate. Every year, many students pass the graduate entrance examination and do their master or doctor degree in the key university in China, such as Automation Research Institute of Chinese Academy of Sciences, Beijing University of Aeronautics and Astronautics, Central China University of Science and Technology, Wuhan university, and so son.

\section{References:}

[1] Wang, Wenkai \& Yao, Anqing. Exploration and Practice of Off-campus practice teaching base construction with Yangtze university agronomy university as a case study [J]. Anhui agricultural science 2007 (29) .

[2]Peng, Xingdong \& Song, Hua. Improve the quality of production internship teaching professional $[\mathrm{J}]$. Journal of liaoning university of science and technology 2009 (5).

[3] Wang, Yansong \&Zhang, Jiasheng. Practice teaching reform of Electrical engineering and its automation specialty [J] . Journal of electrical and electronics teaching 2007 (2) : 86-88. 